\title{
Retrogradation of heat-gelatinized rice grain in sealed packaging: investigation of moisture relocation
}

\author{
Kyung-jin JUNG ${ }^{1}$, Hyunah LEE ${ }^{2}$, Sang Hyun LEE 2 , Jae Cherl KIM²,
}

\begin{abstract}
The aggregation of water molecules inside heat-gelatinized rice grain due to retrogradation of the grain was investigated by textural change and scanning electron microscopy (SEM) analysis of cooked grains after storage at $11^{\circ} \mathrm{C}$ in a sealed package. Relaxation tests using a disc-type tip showed an increase in hardness (strength) of the cooked grain as the degree of retrogradation increased with increasing storage time, measured by the $\alpha$-amylase-iodine method. SEM analysis of the vacuum-dried cooked rice grain showed a gradual increase in crevices, which further developed into holes at the center of the granule with increasing storage time. The results suggest that the disruption of hydrogen bonds between water and starch molecules is the first step for the retrogradation of gelatinized rice grain stored in a hermetic environment to avoid drying, resulting in its increased hardness, followed by the aggregation of starch molecules with subsequent water extrusion.
\end{abstract}

Keywords: rice grain; starch; gelatinization; retrogradation; texture; structure.

Practical Application: Retrogradation of gelatinized rice grain resulted in the loss of sensorial taste during storage.

\section{Introduction}

As a main dietary source of carbohydrates, rice plays an important role in energy requirements and nutrient intake (Ramesh et al., 2000; Ogawa et al., 2003; Park et al., 2012). Contrary to other grains, rice is usually consumed as a whole grain for the main meal (Ramesh et al., 2000; Ogawa et al., 2003). With an increasing demand for pre-cooked rice products, starch retrogradation has become an important quality parameter for the evaluation of prolonged storage (Burgos \& Armada, 2015; Yu et al., 2010). The leached components which cover the surface of rice grain such as starch, nonstarch carbohydrates, lipids and proteins caused by cell disruption inside the granule during cooking process play significant roles in the eating quality of rice (Ogawa et al., 2003). The textural properties of cooked rice are primarily related to its moisture content because of starch gelatinization (Bello et al., 2007; Tamura \& Ogawa, 2012; Kim et al., 2001; Ramesh et al., 2000). The hardness and stickiness of rice grain are the commonly measured parameters in the determination of the textural properties of cooked rice (Meullenet et al., 1998). Consequently, textural changes in cooked rice grain during storage are closely related to starch retrogradation.

The structure of the building unit of starch grains the starch granule is defined in terms of its amorphous and semi-crystalline growth rings (Vandeputte et al., 2003). When a starch suspension is heated in excess water, gelatinization usually leads to a number of changes in the starch granule. The first stage of gelatinization is the uptake of water by the amorphous background region of the starch granules, followed by their subsequent rapid expansion.
This swelling exerts a strong destabilizing effect on the crystallites, followed by the disruption and loss of crystallinity (Tester \& Karkalas, 2002); Karapantsios et al., 2002). Changes in water distribution and internal structure during cooking are closely related to the gelatinization characteristics (Horigane et al., 1999). Retrogradation is usually regarded as the reverse step of gelatinization (Bear \& Samsa, 1943). Increased hardness of the gelatinized whole rice grain, when preserved at low temperatures considerably lower than the gelatinization temperature, causes an uncomfortable chewiness and requires reheating of the rice grain by either conventional heating or microwave. Moisture redistribution due to starch retrogradation affects the texture of gelatinized rice grain during storage in a sealed package.

The effects of the freezing rate on the retrogradation and textural properties of cooked rice grain have been previously investigated (Yu et al., 2010). Kock et al. (1995) reported that hardness increased and stickiness decreased at lower temperatures and longer storage durations. Identification of the structural characteristics of amylose and amylopectin has provided insight into the textural properties of gelatinized rice gel (Vandeputte et al., 2003). Gelatinization and retrogradation are shown to have a strong influence on the textural properties during rice cooking, handling, distribution, and storage (Banchathanakij \& Suphantharika, 2009). Gudmundsson (1994) demonstrated that, upon cooling of gelatinized rice grain, retrogradation occurs when gelatinized starch begins to reassociate in an ordered structure under low energy input, as in cooling and freezing. 
Although many researchers have extensively documented the rheological properties of starch gelatinization and retrogradation associated with the interaction of water and starch molecules in solution (Juliano, 1998; Bao et al., 2006; Wu et al., 2010; Kim et al., 1997), the relationship of retrogradation with increasing hardness of gelatinized rice grain in terms of moisture redistribution under storage conditions, where moisture movement is prohibited to avoid drying at relatively low temperatures, has hardly been studied. Therefore, this study was focused on changes in hardness and structural characteristics of gelatinized rice grain, which can be indicative of the retrogradation process in terms of water redistribution inside the rice grain, under hermetic conditions.

\section{Materials and methods}

\subsection{Materials}

Non-waxy polished short-grain rice (Oryza sativa L.) was obtained from a local market (Gimhae, Korea) and stored at $10^{\circ} \mathrm{C}$. The germ and bran of the rice were completely removed; dust and fine starch particles were also removed by polishing during the milling process. All reagents and chemicals used were of analytical grade (Sigma-Aldrich, St. Louis, MO, USA), unless specified otherwise.

\subsection{Preparation of gelatinized rice grain}

Approximately 1.4 times the volume of water $(\mathrm{v} / \mathrm{w})$ was added to a given amount of rice for gelatinization in an electronic pressure cooker (CRP-FA0610FP, Cuckoo Homesys Co. Ltd., Yangsan, Korea) as usual. The gelatinized rice grains was packaged at $20^{\circ} \mathrm{C}$ and $56 \%$ relative humidity and cooled in a hermetically sealed aluminum laminated pouch $(10 \times 15 \mathrm{~cm})$. The sealed pouch was stored during 9 days at $11^{\circ} \mathrm{C}$ using low temperature incubator (HB-103S, Han Baek Scientific Co., Bucheon, Korea). The moisture content of the rice and gelatinized rice grain was determined using the methods defined by the Association of Official Analytical Chemists (2002). Volume of the raw rice grain and gelatinized grain was obtained by adding 20 grains to a calibrated cylinder and measuring the water volume required to fill up a known graduation.

\subsection{Estimation of hardness and retrogradation of gelatinized rice grain}

The hardness of gelatinized rice grain was determined by the relaxation test using a rheometer (RT-2010DD, Fudoh Co. Ltd., Tokyo, Japan) with a disc-type tip (\#3-3థ) at a table speed of $100 \mathrm{~mm} / \mathrm{min}$. The maximum force required to press a $0.6 \mathrm{~mm}$ distance from the gelatinized rice grain surface was defined as the hardness $\left(g_{f}\right)$ of the gelatinized rice grain. The results are presented as mean values with standard deviation for ten replications. The degree of retrogradation of the gelatinized rice grain was measured by the a-amylase-iodine method (Tsuge et al., 1990). A quantity of gelatinized rice grain $(250 \mathrm{mg})$ was dissolved in $50 \mathrm{~mL}$ of distilled water and homogenized (AM-7, Nihonseiki Kaisha Ltd., Tokyo, Japan) for 1 min twice. $\alpha$-Amylase (2 mL; E.C. 3.2.1.1, Bacillus sp. type II-A, 1,400 unit/mg solid, Sigma-Aldrich, St. Louis, MO, USA) solution (7 units) was dissolved in $5 \mathrm{~mL}$ of the homogenized solution. Distilled water $(3 \mathrm{~mL})$ and $0.1 \mathrm{M}$ phosphate buffer $(2 \mathrm{~mL}$; pH $6,0.3 \% \mathrm{NaCl})$ were added and placed in a shaking water bath at $37^{\circ} \mathrm{C}$ for $15 \mathrm{~min}$. After $5 \mathrm{~mL}$ of $4 \mathrm{~N} \mathrm{NaOH}$ was added to stop the enzymatic reaction, the mixture was adjusted to $\mathrm{pH} 7 \mathrm{using} 4 \mathrm{~N} \mathrm{HCl}$ and to a total volume of $100 \mathrm{~mL}$ by adding distilled water, followed by the addition of $5 \mathrm{~mL}$ of iodine reagent $\left(0.2 \% \mathrm{I}_{2}\right.$ and $\left.2 \% \mathrm{KI}, \mathrm{w} / \mathrm{w}\right)$ and kept at room temperature for $20 \mathrm{~min}$. Absorbances were measured using a UV-Vis spectrophotometer (OPTIZEN POP, Mecasys Co., Daejeon, Korea) at $625 \mathrm{~nm}$. All tests were performed at least in triplicate and results are presented as mean values with standard deviation.

\subsection{Morphological changes of internal structure of gelatinized and retrograded rice grain}

SEM (S-4300SE, Hitachi Ltd., Tokyo, Japan) was used to examine morphological changes inside the gelatinized and retrograded rice grain while being stored at $11^{\circ} \mathrm{C}$ under hermetic conditions. The freeze-dried (FDU-1200, Tokyo Rikakikai Co., Tokyo, Japan) rice grains were carefully cleaved in half along the short axis with a safety razor to avoid any physical damage to the cleaved surface. Cross-sections of the cleaved rice grains were observed after coating with platinum using a sputter coater.

\section{Results and discussion}

\subsection{Textural properties of gelatinized and retrograded rice grain}

Moisture content of the gelatinized rice grain was $63.5 \%(\mathrm{w} / \mathrm{w})$ which represents water was absorbed approximately 1.3 times the weight of raw rice during cooking. Therefore, the volume of a gelatinized rice grain increased 2.24 times compared to that of the raw rice grain. As a consequence hardness decreased dramatically since the absorbed water molecules inside the starch molecules would have acted as a plasticizer (Table 1). Hardness of the raw rice grain exceeded measurement range of the disk type tip of the rheometer. Cho et al. (2004) reported that maximum force required to cut raw waxy rice using cutting type probe was $101 \pm 38 \mathrm{~g}_{\mathrm{f}}$. Rice starch in the endosperm undergoes gelatinization at sufficiently high temperatures. Starch granules expand in volume and press together closely, creating a strong cohesion force between starch molecules and water by hydrogen bonding (Bello et al., 2007). As a consequence strong bonds in both the crystalline and amorphous regions are broken and hydrogen bonds formed between the penetrated water molecules contribute to the increase in grain volume. Therefore, the cooked rice grain is soft, pliable, and elastic resulting in the value of hardness $51.9 \mathrm{~g}_{\mathrm{f}}$ (Table 1). Immediate cooling of the gelatinized rice grain significantly increased grain hardness $\left(78.8 \mathrm{~g}_{\mathrm{f}}\right)$ which presumably suggests that the hydrogen bonds between the water and starch molecules were disrupted considerably to affect the textural properties of grain.

Table 1. Properties of raw and gelatinized rice grain.

\begin{tabular}{lccc}
\hline & $\begin{array}{c}\text { Moisture content } \\
(\text { wt. } \%)\end{array}$ & $\begin{array}{c}\text { Volume } \\
\left(\mathrm{mm}^{3} / \text { grain }\right)\end{array}$ & $\begin{array}{c}\text { Hardness } \\
\left(\mathrm{g}_{\mathrm{f}}\right)\end{array}$ \\
\hline Raw Grain & $14.7 \pm 5.6$ & $14.41 \pm 0.21$ & $-^{*}$ \\
\hline Gelatinized & $61.2 \pm 1.3$ & $32.33 \pm 1.73$ & $51.9 \pm 4.3^{\star \star}$ \\
Grain & & & $78.8 \pm 4.1^{\star * *}$ \\
\hline
\end{tabular}

${ }^{*}$ exceeded measurement range; ${ }^{* *}$ measured immediately after gelatinization; ${ }^{* * *}$ measured at $11^{\circ} \mathrm{C}$. 
The hardness of the whole rice grain continuously increased, reaching a value just below $100 \mathrm{~g}_{\mathrm{f}}$ within 9 day of storage at $11^{\circ} \mathrm{C}$ (Figure 1). A change in the hardness of the whole gelatinized grain with storage time is obviously related to water molecule redistribution with respect to the retrogradation of the starch grain. The retrogradation process leads to the cohesion of starch molecules by the cleavage of hydrogen bonds which in turn promotes the recrystallization of the starch molecules. The degree of retrogradation showed a continuous increase, and was less than $40 \%$ at 9 day storage (Figure 2). Lu et al. (1997) reported that the majority of amylase molecules were retrograded and precipitated from solution after incubating at $5{ }^{\circ} \mathrm{C}$ for 100 days and that the degree of retrogradation decreased from $58.8 \%$ to $7.1 \%$ within $24 \mathrm{~h}$ as incubation temperature was increased from 5 to $45{ }^{\circ} \mathrm{C}$. The retrogradation degree of $50 \%$ non-waxy rice starch gel was more than $45 \%$ over a 6 day storage period under refrigerated conditions (Kim et al., 1996).

Since the gelatinized rice grains were sealed in an aluminum laminated pouch, a void space in the sealed package was almost completely saturated with water vapor at the storage temperature $\left(11^{\circ} \mathrm{C}\right)$. Therefore, the moisture inside the rice grain cannot be diffused out of the grain to a void space in a sealed pouch. As a result, the water molecules exuded from the starch strands was trapped inside the grain matrix. The retrogradation of the steam-gelatinized rice grain was also initiated by the disruption of hydrogen bonds between water and starch molecules, followed by the adhesion of starch molecules with subsequent exclusion of water molecules between the starch strands; these water molecules remained captured in the grain. Starch retrogradation has been reported to result in an increased hardness of cooked rice during storage (Perdon et al., 1999; Yu et al., 2009). The degree of retrogradation, expressed as the change in firmness, of cooked non-waxy rice grain was inversely related to moisture content between 60.5 and $65.9 \%$ (Kim et al., 1996). As the association of starch molecules in gelatinized rice grain increased, more water molecules were expelled and they gathered to form water crevices inside the granule, resulting in the gradual increase in hardness to an eventual plateau value (Figure 2). During the retrogradation process, smaller crystalline regions, which are easily disrupted at low temperature, are first formed; some ordered regions may then aggregate to create a large helix. The large ordered regions, having more hydrogen bonds, are stable and maintained their organized structure at higher temperatures (Matalanis et al., 2009).

\subsection{Internal structure of gelatinized and retrograded rice grain}

The examination of cross-sectional SEM micrographs showed that the gelatinized rice grain appeared to have a typical histological structure with cracks (Figure 3A), as described by Ogawa et al. (2003). Ogawa et al. (2003) suggest that grain of cracks serve as channels for the flow of water into the grain during cooking. It seemed likely that most of the granular form of starch was maintained immediately after grain cooking (Figure $3 \mathrm{~A}$ ). However, moisture redistribution due to retrogradation inside the gelatinized rice grain occurred very rapidly by lowering the temperature (Figure 3B). An increase in the number and size of

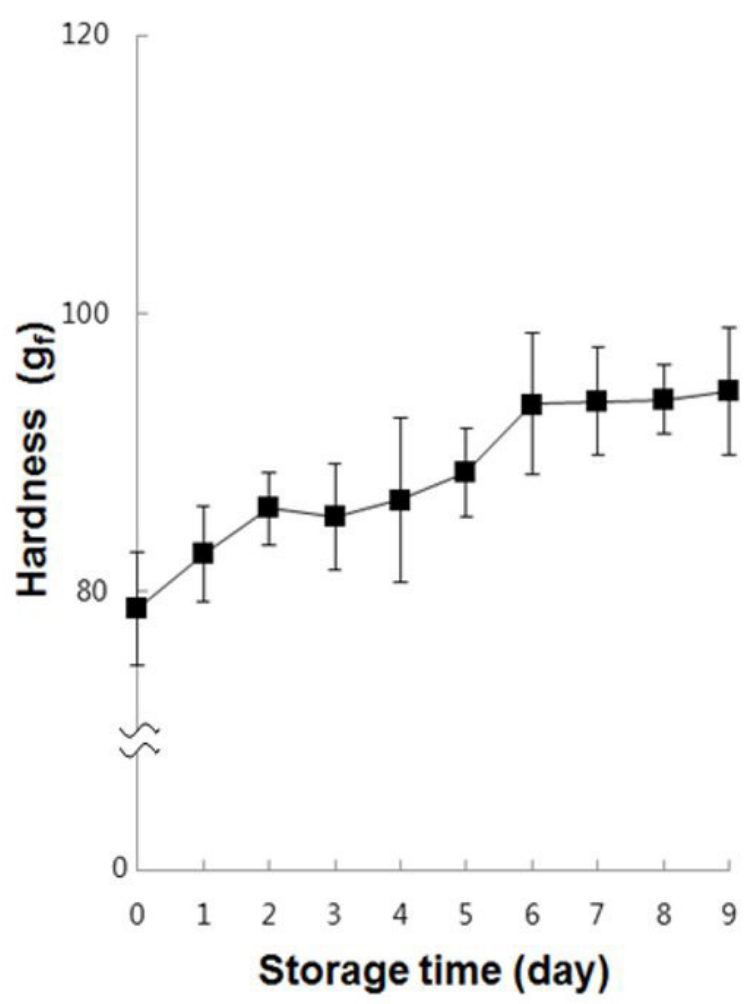

Figure 1. Changes in rice grain hardness $\left(\mathrm{g}_{\mathrm{f}}\right)$ after gelatinization during storage at $11^{\circ} \mathrm{C}$ measured using a disk-type tip.

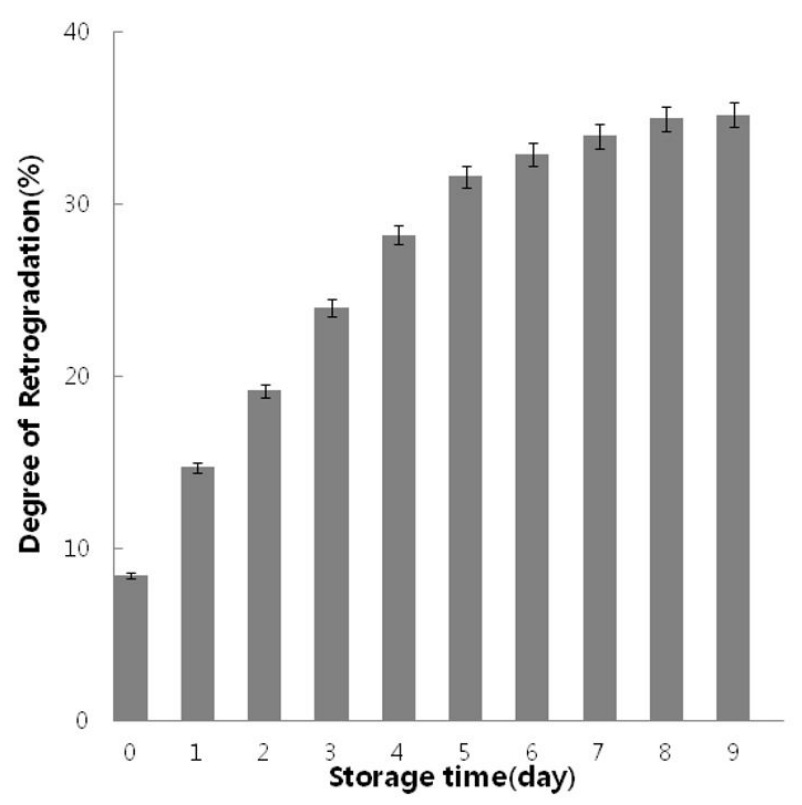

Figure 2. Degree of retrogradation (\%) during storage at $11^{\circ} \mathrm{C}$.

crevices (Figure 3B, C), which developed into holes (Figure 3D) during storage at $11^{\circ} \mathrm{C}$, was prominent. The water molecules were aggregated to form water crevices as a result of starch molecule association due to retrogradation inside the rice grain. Further development of the hole in the center of the grain may indicate the breakage and disintegration of gelatinized starch granules 

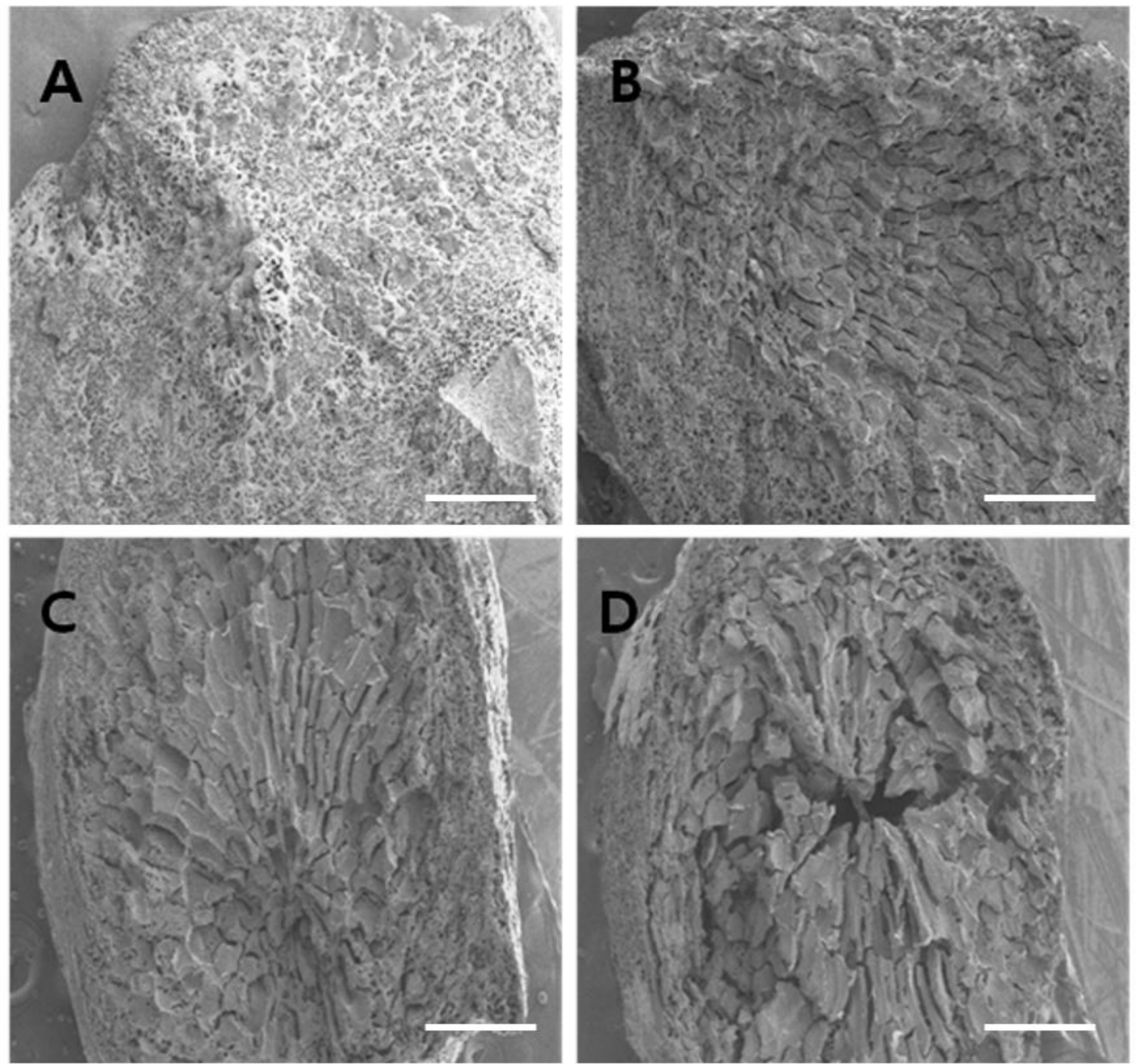

Figure 3. Cross-sectional scanning electron microscopy images of gelatinized rice grain: (A) Immediately after gelatinization without cooling; (B) cooling and 0 day storage at $11^{\circ} \mathrm{C}$; (C) cooling and 2 day storage at $11^{\circ} \mathrm{C}$; (D) cooling and 4 day storage at $11^{\circ} \mathrm{C}$. Scale bars: $500 \mu \mathrm{m}$.

which leads to the separation of water and starch molecules after 4 day storage (Figure 3D). Hollow volumes, which were assumed to originate from the sealing of cracks with gelatinized starch during the cooking process (Horigane et al., 1999, 2000; Ogawa et al., 2003), can also significantly affect the development of water channels and holes as retrogradation continues during storage. Although hardness continuously increased because of starch retrogradation (Figure 1 and 2), SEM micrographs of the cross-section of gelatinized rice grain after 9 day storage revealed virtually the same morphology as that stored for 4 days at $11{ }^{\circ} \mathrm{C}$ (shown in Figure 3D). This result suggests that moisture redistribution between the starches structures occurred quite rapidly, followed by the reassociation of the starch molecules in the retrogradation process, leading to further crystallization. It was observed that the inner porous structure, which developed into crevices, began to form in the center of the cooked rice grain right after cooling (Figure 3B), becoming prominent within a 2 day storage period (Figure 3 C).

\section{Conclusions}

The retrogradation of gelatinized rice grain resulted in an increased hardness of the rice grain with storage time. The reassociation of starch molecules leading to the retrogradation and expulsion of water aggregates from the starch network contributed to an increased hardness of gelatinized rice grain 
during storage. Since water molecules expelled from the starch networks were captured in a starch grain unlike in starch gel, crevices and finally water holes were developed inside the rice grain. SEM analysis of gelatinized and freeze-dried whole rice grain cross-sections showed many crevices in the early stages of low temperature storage, while larger holes were found at a later stage of storage. The degree of retrogradation gradually increased as storage time was increased. It is construed that the cleavage of hydrogen bonds between water and starch molecules was followed by the aggregation of water expelled from starch molecule networks in the gelatinized grain during retrogradation with subsequent formation of water wells inside the rice grain.

\section{Acknowledgements}

This research was supported by Basic Science Research Program through the National Research Foundation of Korea (NRF) funded by the Ministry of Education, Science and Technology (2011-0027262).

\section{References}

Association of Official Analytical Chemists - AOAC. (2002). Official methods of analysis of the Association of Official Analytical Chemists (17th ed.). Arlington: AOAC.

Banchathanakij, R., \& Suphantharika, M. (2009). Effect of different $\beta$-glucans on the gelatinisation and retrogradation of rice starch. Food Chemistry, 114(1), 5-14. http://dx.doi.org/10.1016/j. foodchem.2008.09.016.

Bao, J., Sun, M., \& Corke, H. (2006). Analysis of genotypic diversity in starch thermal and retrogradation properties in nonwaxy rice. Carbohydrate Polymers, 67(2), 174-181. http://dx.doi.org/10.1016/j. carbpol.2006.05.011.

Bear, R., \& Samsa, E. (1943). Gelatinization Mechanism of Starch Granules. Industrial \& Engineering Chemistry, 35(6), 721-726. http:// dx.doi.org/10.1021/ie50402a019.

Bello, M. O., Tolaba, M. P., \& Suarez, C. (2007). Water absorption and starch gelatinization in whole rice grain during soaking. $L W T$ - Food Science and Technology, 40(2), 313-318.

Burgos, V. E., \& Armada, M. (2015). Characterization and nutritional value of precooked products of kiwicha grains (Amaranthus caudatus). Food Science and Technology, 35(3), 531-538. http:// dx.doi.org/10.1590/1678-457X.6767.

Cho, S. B., Chang, H. J., Kim, H. Y., Kim, W. J., \& Chun, H. S. (2004). Steeping-induced physicochemical changes of milled waxy rice and their relation to the quality of $y u k w a$ (an oil-puffed waxy rice snack). Journal of the Science of Food and Agriculture, 84(5), 465-473. http:// dx.doi.org/10.1002/jsfa.1678.

Gudmundsson, M. (1994). Retrogradation of starch and the role of its components. Thermochimica Acta, 246(2), 329-341. http://dx.doi. org/10.1016/0040-6031(94)80100-2.

Horigane, A., Engelaar, W., Toyoshima, H., Ono, H., Sakai, M., Okubo, A., \& Nagata, T. (2000). Differences in hollow volumes in cooked rice grains with various amylose contents as determined by NMR micro imaging. Journal of Food Science, 65(3), 408-412. http://dx.doi. org/10.1111/j.1365-2621.2000.tb16017.x.

Horigane, A., Toyoshima, H., Hemmi, H., Engelaar, W., Okubo, A., \& Nagata, T. (1999). Internal hollows in cooked rice grains (Oryza sativa cv. koshihikari) observed by NMR micro imaging. Journal of
Food Science, 64(1), 1-5. http://dx.doi.org/10.1111/j.1365-2621.1999. tb09849.x.

Juliano, B. O. (1998). Varietal impact on rice quality. Cereal Food World, 43(4), 207-222.

Karapantsios, T., Sakonidou, E., \& Raphaelides, S. (2002). Water dispersion kinetics during starch gelatinization. Carbohydrate Polymers, 49(4), 479-490. http://dx.doi.org/10.1016/S0144-8617(02)00005-X.

Kim, J. K., Kim, S. S., \& Kim, K. O. (2001). Effect of milling ratio on sensory properties of cooked rice and on physicochemical properties of milled and cooked rice. Cereal Chemistry, 78(2), 151-156. http:// dx.doi.org/10.1094/CCHEM.2001.78.2.151.

Kim, J., Kim, W., \& Shin, M. (1997). A comparative study on retrogradation of rice starch gels by DSC, X囚Ray and a冈amylase methods. Stärke, 49(2), 71-75. http://dx.doi.org/10.1002/star.19970490207.

Kim, S., Lee, A., Lee, S., Kim, K., \& Cheon, K. (1996). Firming rates of cooked rice differing in moisture contents. Korean Journal of Food Science and Technology, 28(5), 877-881.

Kock, S., Minnaar, A., Berry, D., \& Taylor, J. (1995). The effect of freezing rate on the quality of cellular and non-cellular par-cooked starchy convenience foods. LWT - Food Science and Technology, 28(1), 8795. http://dx.doi.org/10.1016/S0023-6438(95)80017-4.

Lu, T., Jane, J., \& Keeling, P. L. (1997). Temperature effect on retrogradation rate and crystalline structure of amylose. Carbohydrate Polymers, 33(1), 19-26. http://dx.doi.org/10.1016/S0144-8617(97)00038-6.

Matalanis, A., Campanella, O., \& Hamaker, B. (2009). Storage retrogradation behavior of sorghum, maize and rice starch pastes related to amylopectin fine structure. Journal of Cereal Science, 50(1), 74-81. http://dx.doi.org/10.1016/j.jcs.2009.02.007.

Meullenet, J. F., Kauffmann, D., \& Champagne, E. (1998). Rapid assessment of cooked rice texture characteristics: a method for breeders. In R. J. Norman and T. H. Johnston (Eds.), Rice reserach studies 1998 (pp. 361-370). Little Rock: Arkansas Agricultural Experiment Station.

Ogawa, Y., Glenn, G. M., Orts, W. J., \& Wood, D. F. (2003). Histological structures of cooked rice grain. Journal of Agricultural and Food Chemistry, 51(24), 7019-7023. http://dx.doi.org/10.1021/jf034758o. PMid:14611164.

Park, C., Kim, Y., Park, K., \& Kim, B. (2012). Changes in physicochemical characteristics of rice during storage at different temperatures. Journal of Stored Products Research, 48, 25-29. http://dx.doi.org/10.1016/j. jspr.2011.08.005.

Perdon, A., Siebenmorgen, T., Buescher, R., \& Gbur, E. (1999). Starch retrogradation and texture of cooked milled rice during storage. Journal of Food Science, 64(5), 828-832. http://dx.doi. org/10.1111/j.1365-2621.1999.tb15921.x.

Ramesh, M., Bhattacharya, K., \& Mitchell, J. (2000). Developments in understanding the basis of cooked-rice texture. Critical Reviews in Food Science and Nutrition, 40(6), 449-460. http://dx.doi. org/10.1080/10408690091189220. PMid:11186235.

Tamura, M., \& Ogawa, Y. (2012). Visualization of the coated layer at the surface of rice grain cooked with varying amounts of cooking water. Journal of Cereal Science, 56(2), 404-409. http://dx.doi. org/10.1016/j.jcs.2012.06.002.

Tester, R. F., \& Karkalas, J. (2002). Starch. In E. J. Vandamme, S. De Baets \& A. Steinbüchel (Eds.), Biopolymers (Vol. 6, pp. 381-438). Weinheim: Wiley-VCH.

Tsuge, H., Hishida, M., Iwasaki, H., Watanabe, S., \& Goshima, G. (1990). Enzymatic evaluation for the degree of starch retrogradation in foods and foodstuffs. Stärke, 42(6), 213-216. http://dx.doi.org/10.1002/ star.19900420603. 
Vandeputte, G., Vermeylen, R., Geeroms, J., \& Delcour, J. (2003). Rice starches. III. structural aspects provide insight in amylopectin retrogradation properties and gel texture. Journal of Cereal Science, 38(1), 61-68. http://dx.doi.org/10.1016/S0733-5210(02)00142-X.

Wu, Y., Chen, Z., Li, X., \& Wang, Z. (2010). Retrogradation properties of high amylose rice flour and rice starch by physical modification. LWT-Food Science and Technology, 43(3), 492-497. http://dx.doi. org/10.1016/j.lwt.2009.09.017.
Yu, S., Ma, Y., \& Sun, D. (2009). Impact of amylose content on starch retrogradation and texture of cooked milled rice during storage. Journal of Cereal Science, 50(2), 139-144. http://dx.doi.org/10.1016/j. jcs.2009.04.003.

Yu, S., Ma, Y., \& Sun, D. (2010). Effects of freezing rates on starch retrogradation and textural properties of cooked rice during storage. LWT- Food Science and Technology, 43(7), 1138-1143. http://dx.doi. org/10.1016/j.lwt.2010.03.004. 